\title{
AÇÃO DOS SUCOS DIGESTIVOS SOBRE A ABSORÇÃO E DESTINO DO BCG ORAL
}

\author{
Rodnei C. Mortatti1, Luiz Carlos S. Maia2 e Leila Fonseca1
}

\begin{abstract}
Estudou-se a ação do suco gástrico artificial e suco duodenal humano sobre a vacina $B C G$, bem como a absorção e destino desta após administraçâo intragástrica em camundongos. O contato de 2 horas do bacilo com o suco gástrico provocou uma diminuição significante do consumo de oxigênio e uma moderada perda da viabilidade. $O$ suco duodenal induziu marcante decréscimo da respiração bacilar e grande reduçāo da viabilidade. O BCG foi marcado com carbono-14 usando-se 14 C-glicerol como precursor dos lipidios micobacterianos. Niveis similares de radioatividade foram obtidos nos órgãos dos animais, 24 horas após administração intragástrica de ${ }^{14} C$ $B C G,{ }^{14} C$-BCG rompido por ultra-som e ${ }^{14} C$-glicerol. Os niveis de $14 C-B C G$ permaneceram estáveis do 6.0 ao $24 .^{\circ}$ dia, enquanto o sonicado de ${ }^{14} C-B C G$ e 14 -glicerol definiram um processo de decaimento biologico. As curvas de biodecaimento no intestino delgado e no figado indicaram que o processo de absorção foi desencadeado rapidamente e alcançou seu nível máximo às 24 horas, decaindo em seguida de acordo com a complexidade química do material dado aos camundongos. Não foram isolados bacilos viaveis dos órgãos dos animais que receberam BCG não marcado. Pode-se concluir, portanto, que a maioria dos bacilos foram absorvidos intactos mas não viáveis.
\end{abstract}

Palavras chaves: Micobactéria. BCG oral. Sucos digestivos. Carbono-14. Absorção. Biodisponibilidade.

De 1921 até poucos anos atrás, a vacina BCG foi administrada pela via oral a milhões de pessoas, na tentativa de induzir proteção contra a tuberculose. Devido a razóes operacionais e econômicas, esta via foi abandonada sem uma conclusão final sobre sua absorção gastrintestinal. Todavia, resposta de hipersensibilidade retardada ao PPD após administração oral do BCG em humanos 12182023 e cobaios ${ }^{819}$ tem sido aceita como evidência da relevância do $\mathrm{BCG}$ oral para o sistema imune. Recentemente, administraçāo de BCG oral como um estimulante imunológico inespecifico, foi estendida à imunoterapia do câncer em modelos animais $^{4528}$ e pacientes humanos 162529 . Melhoria do estado imunológico de pacientes com câncer avançado pode ser alcançado sem reaçōes adversas, mesmo após doses maciças de BCG oral ${ }^{30}$.

Após doses orais repetidas, poucas unidades viáveis de $\mathrm{BCG}$ foram recuperadas de órgãos de

1. Departamentos de Imunologia e Microbiologia Médica. Instituto de Microbiologia, Universidade Federal do Rio de Janeiro.

2. Fundação Ataulpho de Paiva, Rio de Janeiro.

Financiado pelo Conselho Nacional de Desenvolvimento Científico e Tecnológico (CNPq) e Fundação Ataulpho de Paiva.

Endereço para correspondência: Dr. Rodnei C. Mortatti, Depto de Imunologia, Instituto de Microbiologia, UFRJ, CCS, Bloco I. 21941, Rio de Janeiro, RJ. Brasil.

Recebido para publicação em 10/3/86. cobaios, camundongos e humanos, e interpretados como uma evidência de sua absorção pelo trato gastrintestinal 682128 . Contudo, a sensibilidade do BCG ao processo digestivo, a quantificação dos bacilos absorvidos e o seu destino no hospedeiro são questões que permanecem sem resposta. Na tentativa de examinar tais questões, nós tratamos $\mathrm{BCG}$ viável com os sucos digestivos in vitro, traçamos a biodistribuição de bacilos marcados com carbono-14 e enumeramos os bacilos viáveis nos órgãos dos camundongos.

\section{MATERIAL E MÉTODOS}

Animais-Foram usados camundongos SW55/Tor fêmeas, produzidas por acasalamento aleatório em colônias fechadas (Dr. S. T. Torres, Universidade Federal Fluminense, RJ). Os animais foram alimentados com ração granulada comercial e água acidificada ad libitum.

Vacina BCG - Foi usada a estirpe Moreau (Rio de Janeiro), produzida comercialmente pela Fundaçào Ataulpho de Paiva. Esta estirpe vem sendo cultivada há vários anos na superfície de meio IVM que possui a seguinte composição por litro: citrato de sódio, $2 \mathrm{~g}$; sulfato de magnésio, $0,5 \mathrm{~g}$; fosfato de potássio, $0,5 \mathrm{~g}$; glutamato de sódio, $1 \mathrm{~g}$; pectona, $16,6 \mathrm{~g}$; amido, $1 \mathrm{~g}$; citrato férrico amoniacal a $15 \%(\mathrm{p} / \mathrm{v}), 0,4 \mathrm{ml}$ e glicerol, $60 \mathrm{ml}$. Nos experimentos de marcação empregou-se também meio IVM sem adição de glicerol (IVM-GF). 
Mortatti RC, Maia LCS, Fonseca L. Ação dos sucos digestivos sobre a absorção e destino do BCG oral. Revista da Sociedade Brasileira de Medicina Tropical 19: 251-258, Out-Dez, 1986.

Ação dos sucos digestivos sobre o BCG - Suco gástrico artificial $\mathrm{pH} 1,92$ foi preparado como descrito $^{22}$. Suco duodenal $\mathrm{pH} 6,7$ foi obtido por entubação gastroduodenal de doadores humanos. Diluiu-se $20 \mathrm{mg}$ ( $1 \mathrm{ml}$ ) de vacina BCG liquida em $2 \mathrm{ml}$ de suco gástrico ( $\mathrm{pH}$ final 3,2) ou suco duodenal ( $\mathrm{pH}$ final 7,2) ou ainda tampão de fosfatos-salina (PBS, $\mathrm{pH} \mathrm{7,4)} \mathrm{e}$ inoculou-se em frascos de Warburg. $\mathrm{O}$ consumo de oxigênio foi medido ao cabo de 30,60 e 120 minutos a $37^{\circ} \mathrm{C}$ em 3 a 8 réplicas, por técnica padrão de Warburg. Para estimar a viabilidade após $30 \mathrm{e}$ $120 \mathrm{~min} ., 0,1 \mathrm{ml}$ da mistura de reação foi diluida em solução salina isotônica até $1: 100.000,1: 200.000 \mathrm{e}$ 1:400.000, inoculada em 5 a 10 réplicas em meio de Ogawa e incubadas a $37^{\circ} \mathrm{C}$ por 6 semanas. Quando se contou o número de particulas viáveis, os resultados foram computados para análise de variância e os valores de probabilidade calculados por teste-t entre as médias $^{3}$.

Marcação do $B C G$ - BCG marcado com carbono-14 foi preparado como descrito para $\mathrm{Myco}$ bacterium phlei ${ }^{27}$, mas com as seguintes modificações: inoculou-se $100 \mathrm{mg}$ (peso seco) de vacina liquida em $10 \mathrm{ml}$ de meios IVM ou IVM-GF, contendo $250 \mu \mathrm{Ci}$ de $1,3-{ }^{14} \mathrm{C}$ glicerol (New England Nuclear, NEN, Mass., USA, atividade especifica $40.8 \mathrm{mCi} / \mathrm{mmol}$ ) e incubou-se a $37^{\circ} \mathrm{C}$ sob agitação leve e constante. Após 14 dias, os bacilos foram colhidos por centrifugação e lavados $(10,000 \mathrm{xg}$, $15 \mathrm{~min}, 4^{\circ} \mathrm{C}$ ) com água destilada, até que a contagem do líquido sobrenadante fosse reduzida ao nivel daquela obtida com água destilada. $O$ rendimento de marcação e a atividade especifica do BCG marcado foram calculados em amostras solubilizadas com hidróxido de amônio quaternário $0,5 \mathrm{M}$ (Protosol, NEN, USA) a $55^{\circ} \mathrm{C}$ por 18 horas de acordo com instrução do fabricante. As amostras digeridas foram diluidas em Econofluor (NEM, USA) e contadas (Beckman $3155 \mathrm{P}$ cintilador líquido).

Experimentos de absorção - Três grupos de 18 animais receberam os seguintes tratamentos intragástricos: $5 \mathrm{mg}(0,45 \mu \mathrm{Ci})$ de ${ }^{14} \mathrm{C}-\mathrm{BCG}, 2,5 \mathrm{mg}(0,23 \mu \mathrm{Ci})$ de ${ }^{14} \mathrm{C}-\mathrm{BCG}$ rompido pelo ultra-som por $15 \mathrm{~min}$. em disruptor sônico (Heat System Ultrasonics, N.Y., USA) como descrito ${ }^{11}$ e $0,25 \mu \mathrm{Ci}$ de ${ }^{14} \mathrm{C}$-glicerol. Todas as soluções foram diluídas em salina isotônica $\mathrm{e}$ administradas através de sonda gástrica para alimentação de prematuros (Sherwood Inc. USA). Os animais sangrados pelo plexo axilar no $1{ }^{\circ}, 6{ }^{\circ}, 12^{\circ}$ e 24 ? dias após o tratamento tiveram os intestinos, figado, gânglios mesentéricos, baço e pulmões removidos. Os órgãos foram lavados com salina ișotônica, cortados, fixados em formalina tamponada $\mathrm{pH} 7,2$ e pesados após adsorção do líquido em excesso. Diversas amostras dos órgãos, incluindo duodeno, ileo (contendo placas de Peyer), ceco e região coloretal foram removidas. As amostras de sangue foram preparadas por digestão com mistura 1:2 Protosol: etanol por 1 hora a $60^{\circ} \mathrm{C}$, de acordo com as instruçōes dos fabricantes. As amostras de órgãos foram solubilizadas com Protosol por 48 horas a $55^{\circ} \mathrm{C}$. As amostras foram, em seguida, diluidas em Biofluor (NEN) e contadas. A percentagem de recuperação foi calculada pela adição das leituras das amostras dos órgãos e projetadas para o peso total dos órgãos. Os resultados foram representados como percentagem da dose administrada. Para determinar a taxa de decaimento biológico, os dados sobre a recuperação total, do figado e do intestino delgado foram tratados por análise de regressão curvilinear ${ }^{26}$.

Contagem de unidades viáveis'de BCG nos órgãos-Um, 6, 12 e 24 dias após a instilação intragástrica de 5 ou $50 \mathrm{mg}$ de vacina BCG líquida, grupos de 3 animais selecionados aleatoriamente foram sacrificados tendo os pulmões, fígado, baço e gânglios mesentéricos removidos assepticamente $\mathrm{e}$ homogenizados em gral de vidro com pistilo de teflon acoplado a motor de alta rotação, em $5 \mathrm{ml}$ de salina estéril contendo $0,2 \%$ de soroalbumina bovina (no a-4503, Sigma Chemical Co., MO., USA). Nos fragmentos de intestinos, as fezes foram expelidas com $30 \mathrm{ml}$ de salina estéril antes da homogeneização. Diluiçóes apropriadas do homogenado foram semeados em agar Middlebrook 7H10, contendo $20 \mu \mathrm{g}$ de ácido nalidixico, $10 \mu \mathrm{g}$ de anfotericina $\mathrm{B}$ e $50 \mathrm{U}$ de penicilina por $\mathrm{ml}$. As placas foram incubadas em embalagens seladas por 4 semanas a $37^{\circ} \mathrm{C}$. Amostras de $0,1 \mathrm{ml}$ de sangue foram também incubados em agar 7H10. Determinou-se a viabilidade dos inóculos orais pela contagem de unidades viáveis imediatamente após a administração intragástrica, semeando-se diluições adequadas do inóculo (fator de 10 ) em placas de agar 7H10 contendo antibióticos, como indicado acima.

\section{RESULTADOS}

Ação dos sucos disgestivos sobre o BCG Antes de embarcar no estudo da absorção gastrintestinal de Mycobacterium bovis BCG, pareceu interessante estudar o comportamento das células bacterianas quando tratadas pelo suco gástrico (SG) e suco duodenal (SD). A atividade inibitória do SG e SD sobre a vacina BCG é mostrada na Figura 1. Foi de $0,019 \mu \mathrm{moles} / \mathrm{mg}$ a taxa de consumo de oxigênio pelos bacilos após contato de $30 \mathrm{~min}$. com o SG enquanto o BCG incubado em PBS consumiu $0,027 \mu \mathrm{moles} / \mathrm{mg}(\mathrm{p}<0,05)$. Não se achou alteração da viabilidade dos bacilos ao fim desse tempo (Tabela 1). Os bacilos toleraram esse tratamento ate $60 \mathrm{~min}$., quando o consumo de oxigênio foi similar ao BCG em PBS $(0,07 \mu \mathrm{moles} / \mathrm{mg})$. $O$ sofrimento bacteriano se 
Mortatti RC, Maia LCS, Fonseca L. Ação dos sucos digestivos sobre a absorção e destino do BCG oral. Revista da Sociedade Brasileira de Medicina Tropical 19: 251-258, Out-Dez, 1986.

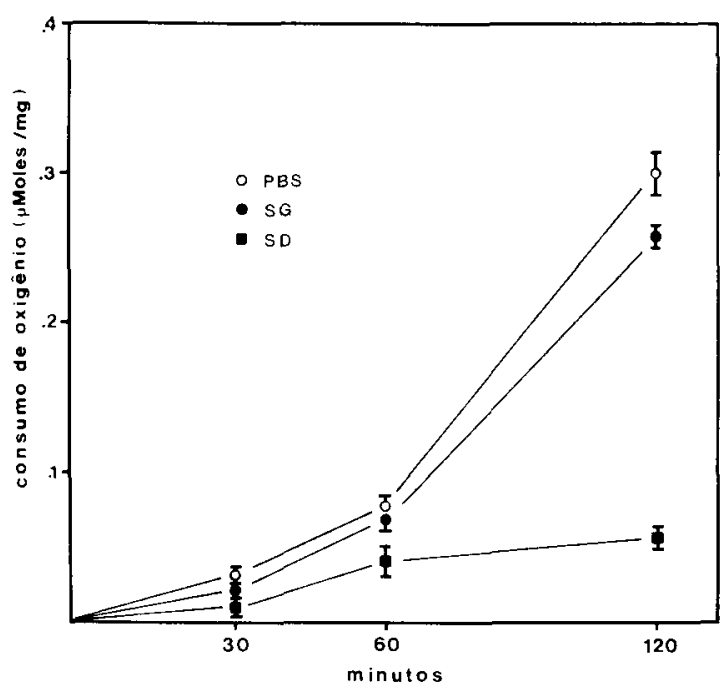

Fig. 1 - Consumo de oxigênio pelo $B C G$ durante tratamento com suco gástrico (SG) e suco duodenal (SD). tornou detectável aos 120 min., com consumo de oxigênio de $0,258 \mu$ moles pelo SG-BCG comparado com $0,3 \mu$ moles pelo PBS-BCG $(p<0,05)$. A viabilidade nesse momento foi $7,1 \times 10^{5}$ partículas viáveis por mg, o que significou uma redução de $40 \%$ na sobrevivência ( $p<0,05$, Tabela 1$)$.

O suco duodenal foi mais danoso para célula de BCG que o suco gástrico. Após $30 \mathrm{~min}$ de contato, BCG consumiu $0,01 \mu$ moles de $\mathrm{O}_{2}$ por $\mathrm{mg}$, menos que a metade de PBS-BCG ( $p<0,001)$. Esta alteração não induziu perda da viabilidade como mostra a contagem de bacilos viáveis na Tabela 1 . Até $60 \mathrm{~min}$. de incubação com SD, houve suficiente aumento da respiração celular para manter a diferença dos controles em torno de $50 \%(p<0,001)$. Intenso sofrimento bacteriano foi evidenciado dos 60 aos $120 \mathrm{~min}$. de contato com o SD, com decréscimo de $80 \%$ no consumo de $\mathrm{O}_{2}(0,058 \mu \mathrm{moles} / \mathrm{mg})$ quando comparado aos controles $(\mathrm{p}<0,001)$, resultando em drástica redução na contagem de particulas viáveis $(65 \%$, $\mathrm{p}<0,005$, Tabela 1).

Tabela 1 - Viabilidade de BCG após tratamento com PBS, suco gástrico (SG) e suco duodenal (SD) ${ }^{a}$

\begin{tabular}{|c|c|c|c|}
\hline \multirow{2}{*}{$B C G$ em: $b$} & \multicolumn{2}{|c|}{ Contagem de viáveis $\left(X 10^{6}\right)$ após: } & \multirow[b]{2}{*}{ Mortalidade } \\
\hline & $30 \mathrm{~min}$. & $120 \mathrm{~min}$. & \\
\hline PBS & $1,9 \pm 0,55 \mathrm{c}$ & $2,3 \pm 0,50$ & 0 \\
\hline Suco gástrico & $1,21 \pm 0,39$ & $0,71 \pm 0,18$ & $40 \%$ \\
\hline Suco duodenal & $3,2 \pm 0,55$ & $1,2 \pm 0,32$ & $65 \%$ \\
\hline
\end{tabular}

Marcação de BCG-Como è mostrado na Tabela 2, bacilos crescendo em meio IVM completo. (contendo 6\% de glicerol não marcado) incorporaram $0,002 \mu$ moles de ${ }^{14} \mathrm{C}$-glicerol (rendimento de marcaçào $=0,2 \%$ ). Em meio IVM-GF a incorporação aumentou 18 vezes, alcançando $0,22 \mu$ moles de ${ }^{14} \mathrm{C}$-glicerol por cada $100 \mathrm{mg}$ de BCG $(3,6 \%$ de rendimento). $\mathrm{O}$ destino dos carbonos assimilados foram discutidos alhures ${ }^{27}$ mas a maioria das moléculas com carbono-14 está associada aos lipídios micobacterianos.

Absorção e destino do ${ }^{14} C-B C G-\mathrm{A}$ absorção total e a biodistribuição de ${ }^{14} \mathrm{C}$-BCG em camundongos tratados pela via oral estão resumidas na Tabela 3 . A absorção total foi considerada como a soma das leituras obtidas em todos os órgãos nas primeiras 24 horas. A Tabela 3 assinala a alta recuperação obtida no figado e intestino delgado, em contraste com as recuperações nos demais órgàos. Observando estes dados, duas importantes questões devem ser formuladas. Primeiro, quais eram as condições de integridade celular do BCG após o evento absortivo, tendo em mente a ação lesiva dos sucos digestivos. Segundo, se o patamar alcançado pelo ${ }^{14} \mathrm{C}-\mathrm{BCG}$ no fígado entre os dias 6 e 24 (diferenças mostradas não são significantes) estaria mantido pelo BCG inteiro ou por seus produtos de digestão. Com o fito de elucidar estas questões, dois controles foram introduzidos: o sonicado de ${ }^{14} \mathrm{C}$-BCG para simular a digestão parcial e o ${ }^{14} \mathrm{C}$-glicerol para representar a solubilização total dos lipidios micobacterianos. A Figura 2 mostra que 5\% da radioatividade administrada com ${ }^{14} \mathrm{C}-\mathrm{BCG}$ foi 
Mortatti RC, Maia LCS, Fonseca L. Ação dos sucos digestivos sobre a absorção e destino do BCG oral. Revista da Sociedade Brasileira de Medicina Tropical 19: 251-258, Out-Dez, 1986.

Tabela 2 - Incorporação del $1,3-14 \mathrm{~d}$ glicerol pelo BCG em meios IVM e IVM-GFa.

\begin{tabular}{lcc}
\hline & $I V M^{b}$ & $I V M-G F^{c}$ \\
\cline { 2 - 3 } $\begin{array}{l}\text { Contagem d } \\
\text { (cpm/mg) }\end{array}$ & 4.500 & 167.000 \\
$\begin{array}{l}\text { Atividade } \\
\text { (dpm/mg) }\end{array}$ & 4.600 & 200.000 \\
$\begin{array}{l}\text { Atividade especifica. } \\
(\mu \text { Cimg) }\end{array}$ & 0,002 & 0,09 \\
Rendimento (\%) & 0,2 & 3,6 \\
\hline
\end{tabular}

a Culturas de 14 dias a $37^{\circ} \mathrm{C}$ sob permanente agitação.

b Contendo $6 \%$ de glicerol'não marcado

c Meio sem glicerol

d Contagens radioativas realizadas em cintilador liquido Beckman $3155 \mathrm{P}$ a $251^{\circ} \mathrm{C}$

Eficiència de contagem para ${ }^{14} \mathrm{C}=98 \%$

Tabela 3 - Biodistribuição de ${ }^{14} C-B C G$ administrado intragastricamente em camundongos $a$

\begin{tabular}{|c|c|c|c|c|}
\hline & \multicolumn{4}{|c|}{ Dias } \\
\hline & 1 & 6 & 12 & 24 \\
\hline Recuperação total & $5,51 \pm 0,40^{b}$ & $1,65 \pm 0,19$ & $1,49 \pm 0,05$ & $1,43 \pm 0,04$ \\
\hline Figado & $1,98 \pm 0,53$ & $0,55 \pm 0,11$ & $0,50 \pm 0,13$ & $0,64 \pm 0,01$ \\
\hline Baço & $0,11 \pm 0,01$ & $0,04 \pm 0,01$ & $0,11 \pm 0,04$ & $0,15 \pm 0,06$ \\
\hline Gânglios mesentéricos & $0,15 \pm 0,01$ & $0,15 \pm 0,01$ & $0,16 \pm 0,01$ & $0,10 \pm 0,02$ \\
\hline Intestino delgado & $2,12 \pm 0,21$ & $0,49 \pm 0,06$ & $0,33 \pm 0,09$ & $0,27 \pm 0,06$ \\
\hline Intestino grosso & $0,077 \pm 0,11$ & $0,26 \pm 0,09$ & $0,23 \pm 0,07$ & $0,13 \pm 0,02$ \\
\hline Pulmões & $0,07 \pm 0,02$ & $0,04 \pm 0,01$ & $0,09 \pm 0,02$ & $0,08 \pm 0,02$ \\
\hline Sangue $c$ & $0,31 \pm 0,01$ & $0,13 \pm 0,01$ & $0,07 \pm 0,03$ & $0,06 \pm 0,02$ \\
\hline
\end{tabular}

animais receberam $5 \mathrm{mg}(0,45 \mu \mathrm{Ci})$ de ${ }^{14} \mathrm{C}-\mathrm{BCG}$ por via intragástrica.

b Percentagem da dose administrada. Média \pm erro padrāo da média.

c Corrigido para $1,5 \mathrm{ml}$ (volume médio do sangue total de camundongos).

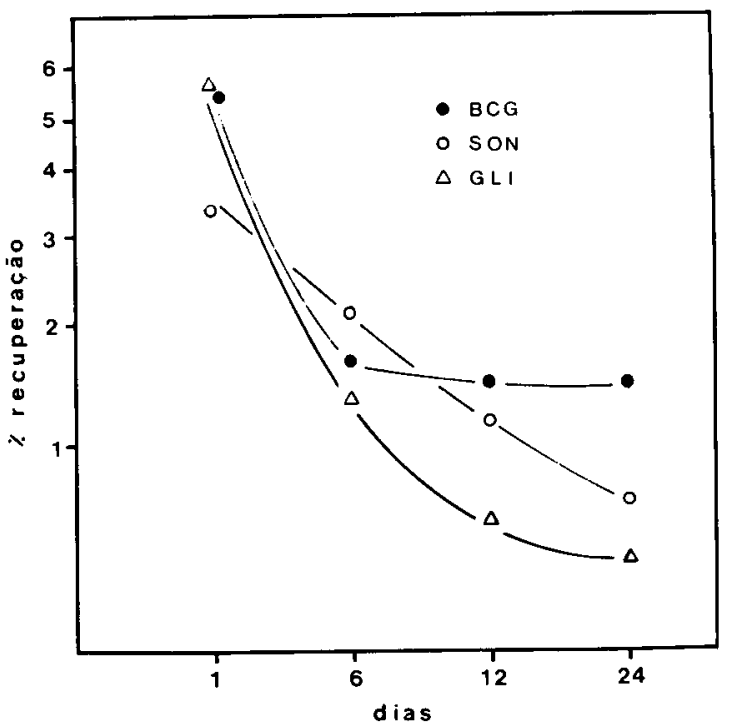

Fig. 2 - Recuperação total e decaimento biológico do ${ }^{14} C-B C G,{ }^{14} C-B C G$ sonicado e ${ }^{14} C$-glicerol após administração intragástrica em camundongos. recuperada nos órgãos após 24 horas, caindo a 1,5\% pelo dia 6 e permanecendo estável até o 24. dia. Se sonicado, o ${ }^{14} \mathrm{C}$-BCG teve um menor nivel de absorção e mostrou um processo regular de biodecaimento (decaimento exponencial, $r^{2}=0,998$ ) com $4 \%$ de radioatividade recuperada no 1 ? dia e $0,5 \%$ no 24 \% dia. $\mathrm{O}$ decaimento do ${ }^{14} \mathrm{C}$-glicerol foi rápido (função potència, $r^{2}=0,990$ ) mostrando $6 \%$ no dia $1 \mathrm{e}$ reduzindo-se 12 vezes e 20 vezes nos dias 12 e 24 respectivamente.

Do intestino delgado foram recuperados no 1 ? dia cerca de $2 \%$ da radioatividade administrada com ${ }^{14} \mathrm{C}$-BCG (Fig. 3). A atividade decaiu em função potência $\left(\mathrm{r}^{2}=0,940\right)$ até $0,25 \%$ no $24 \%$ dia. Observou-se um padrão similar de decaimento com o sonicado de ${ }^{14} \mathrm{C}-\mathrm{BCG}\left(\mathrm{r}^{2}=0,990\right)$ dando $1,3 \%$ no 1 ? dia e $0,2 \%$ no $24 \%$ dia. O biodecaimento do ${ }^{14} \mathrm{C}$-glicerol foi rápido (função potência, $\mathrm{r}^{2}=0,980$ ), dando leituras de $2 \%$ no dia 1 e caindo a niveis praticamente indetectáveis após o $12{ }^{\circ}$ dia. O padrão potência das curvas de biodecaimento mostra que o intestino delgado é um órgão de passagem, com pouca capacidade de retenção para as células BCG inteiras ou de seus produtos derivados. 


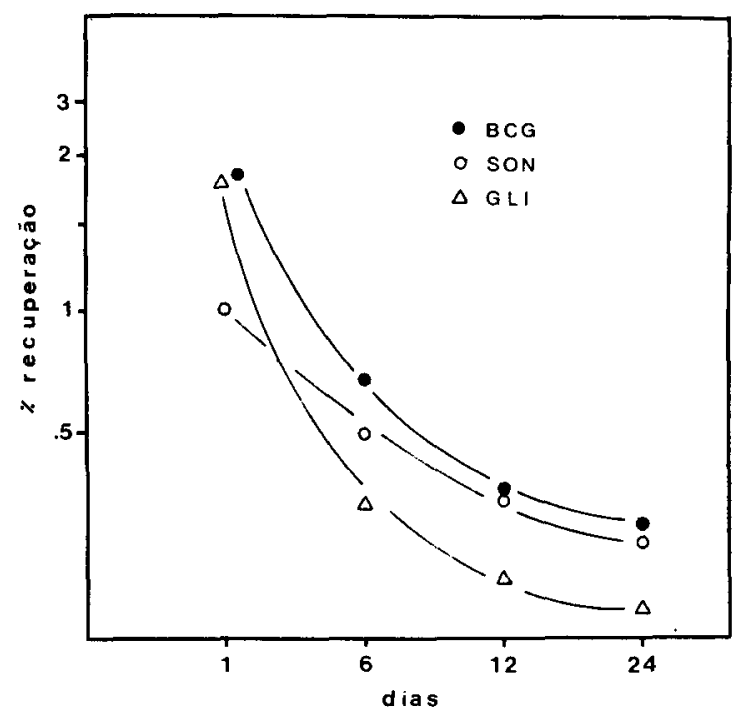

Fig. 3-Recuperaçāo e decaimento biológico do ${ }^{14} C-B C G,{ }^{14} C-B C G$ sonicado e ${ }^{14} C$-glicerol no intestino delgado de camundongos após administração intragástrica.

Findo o $1 \%$ dia, a radioatividade detectada no figado dos animais tratados pelo ${ }^{14} \mathrm{C}$-glicerol compreenderam cerca de $2 \%$ da dose administrada (Fig. 4 ),

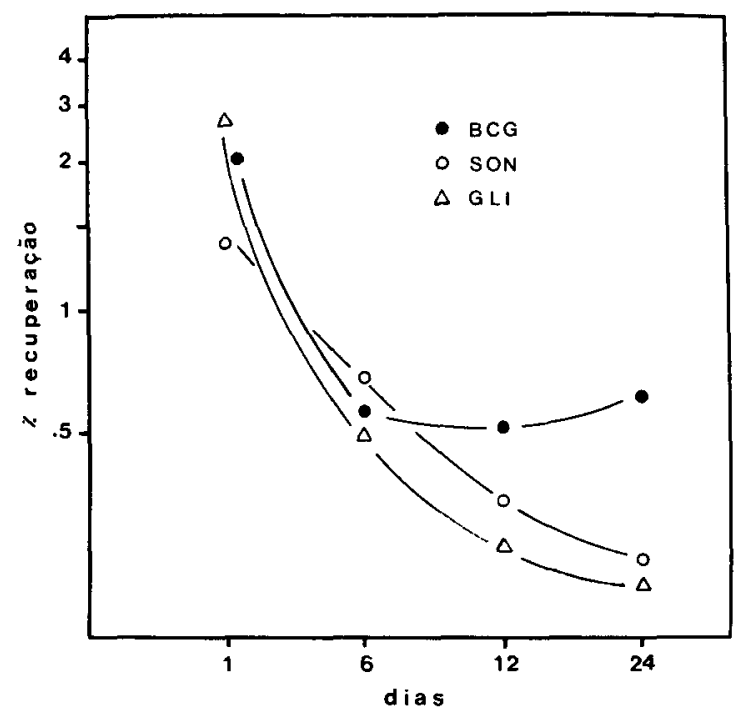

Fig. 4-Recuperaçāo e decaimento biológico do ${ }^{14} C-B C G,{ }^{14} C-B C G$ sonicado e ${ }^{14} C$-glicerol no figado de camundongos após administração intragástrica.

enquanto ${ }^{14} \mathrm{C}$-BCG sonicado mostrou $1,4 \%$. Nos dias subseqüentes, $\mathrm{O}^{14} \mathrm{C}$-glicerol decaiu continuamente em função potência $\left(r^{2}=0,990\right)$. Já o ${ }^{14} \mathrm{C}-\mathrm{BCG}$ sonicado decaiu exponencialmente $\left(r^{2}=0,960\right)$ porque, sendo uma mistura de diversos compostos e macroagregados está, provavelmente, sofrendo diferentes processos de eliminação. Foram consideradas despreziveis a quantidade de radioatividade de ambos os produtos achados no 24 . dia. Em contraste, ${ }^{14} \mathrm{C}-\mathrm{BCG}$ alcançou um patamar do $60^{\circ}$ ao $24 \%$ dias, provendo leituras constantes em torno de $0,5 \%$.

Contagem de unidades viáveis de BCG nos órgãos - A despeito da inclusão do sonicado de ${ }^{14} \mathrm{C}$ BCG e do ${ }^{14} \mathrm{C}$-glicerol como controles para o estudo da absorção de BCG, argumenta-se que a enumeração de bactérias usando recuperação de radioatividade em diferentes órgãos, não expressa o número real de bacilos BCG viáveis nos órgãos. Por conseguinte, foram contadas as particulas viáveis no figado, pulmões, baço, intestinos, linfonodos mesertéricos e sangue. Realizaram-se esses experimentos por 3 vezes, dois dos quais com inóculo de $5 \mathrm{mg}$ de BCG e um outro usando inóculo de $50 \mathrm{mg}$ de BCG. Em nenhuma ocasião, particulas viáveis de BCG puderam ser recuperadas dos órgãos ou do sangue.

\section{DISCUSSÃO}

Diversos relatos 689152128 têm mostrado que uma porção significante de BCG viável administrado oralmente pode alcançar o intestino delgado, mas poucos bacilos passam pelas placas de Peyer e alcançam os demais órgāos. Todavia, a influência do processo digestivo na sobrevivência dos bacilos não fora ainda estudada.

Os resultados relatados aqui mostram um efeito nocivo, tempo-dependente, do suco gástrico sobre a vacina BCG. Experimentos de respiração bacilar mostraram que a ação lesiva do suco gástrico pode ser tolerada por, no máximo, 1 hora sem perda significante da viabilidade. Contudo, o intenso dano induzido pelo suco duodenal sobre o BCG sugere que vários fatores, alèm do baixo $\mathrm{pH}$, devem estar implicados na sobrevivência dos microorganismos dentro do trato digestivo. Ainda que o efeito nocivo do suco duodenal comece logo aos $30 \mathrm{~min}$ de contato provocando uma intensa depressão da respiração bacilar, o BCG pode sobreviver sem significante redução da viabilidade se transferido para meio de cultura fresco. Entre 1 a 2 horas de contato com suco duodenal, as alteraçōes metabólicas dos bacilos se tornam irreversiveis $e$ a viabilidade cai fortemente.

Os estudos sobre a absorção de material marcado com carbono-14 indicam que ${ }^{14} \mathrm{C}-\mathrm{BCG}$ viável ou tratado pelo ultra-som e o ${ }^{14} \mathrm{C}$-glicerol são absorvidos em proporções similares e prontamente recuperados dos órgãos dos camundongos ao fim do 10 dia. As diferenças na persistência de cada produto dentro do organismo são percebidas comparando a inclinação 
Mortatti RC, Maia LCS, Fonseca L. Ação dos sucos digestivos sobre a absorção e destino do BCG oral. Revista da Sociedade Brasileira de Medicina Tropical 19: 251-258, Out-Dez, 1986.

das curvas de biodecaimento. As diferenças dos padrões de decaimento podem ser correlacionadas à natureza ou complexidade quimica de cada material. O nivel estável mantido do $6^{\circ}$ ao $24 \%^{\circ}$ dia, correspondeu a terça parte da radioatividade total recuperada no 1. dia e sugere que, pelo menos, a integridade bacilar foi mantida após absorção. Esta proporção concorda com a proporção do BCG que sobreviveu ao tratamento com suco duodenal. Graus variáveis de persistência foram também vistos traçando o biodecaimento no intestino delgado. É importante enfatizar que o biodecaimento do intestino delgado pode ser interpretado como sendo o evento absortivo das células de BCG viáveis ou de seus produtos.

Publicaçōes previas enfatizaram o importante papel do tecido linfóide associado ao intestino (GALT) na absorção de material particulado ${ }^{3}{ }^{14}$. A camada epitelial do GALT é penetrável por material particulado, que é subseqüentemente fagocitado pelos macrófagos da zona subepitelial. É necessário longa exposição para se obter grande quantidade de partículas de carvão ou de látex em macrófagos subepiteliais ${ }^{12} 13$. A presença de particulas de látex de poliestireno em células epiteliais, lâmina própria e sinusóides hepáticos pode ser demonstrada poucas horas após instilação gástrica em ratos ${ }^{24}$. Entretanto, achouse nos gânglios linfáticos mesentéricos e outros órgãos apenas uma pequena porção de tal material particulado. Células viáveis de Salmonella enteritidis foram detectadas na mucosa ileal, bem como em suas placas de Peyer 12 horas após administração oral em camundongos. Os gânglios de drenagem foram alcançados 48 horas mais tarde, mas nào se achou salmonela no figado e baço antes de 54 horas após a inoculação 7 . De outro modo, a invasão de tecido e a sobrevida de Listeria monocytogenes nos intestinos após inoculaçào oral, parece estar restrita a placas de Peyer, posto que nenhum organismo pode ser cultivado da mucosa intestinal livre das placas de Peyer ${ }^{17}$. Similarmente, somente 48 horas após administração oral foi possivel o isolamento de $L$. monocytogenes do fígado e do baço. Nossos dados mostram que o processo absortivo do ${ }^{14} \mathrm{C}-\mathrm{BCG}$ e seus derivados no intestino delgado, é suficientemente vigoroso para induzir altas contagens no figado 24 horas depois e parece ser independente da viabilidade bacilar. Como a passagem do BCG através do trato intestinal não se completou até 24 horas, parece que parte do BCG ou seus produtos podem ser retidos em macrófagos intestinais. É possível que a absorção do BCG ocorra através das células epiteliais. Sua fácil deteção no figado 24 horas mais tarde, a niveis comparáveis ao ${ }^{14} \mathrm{C}$-glicerol consubstancia esta afirmação. A quantidade desprezivel de radioatividade achada nos gânglios mesentéricos durante os experimentos, indica que o BCG e seus produtos podem alcançar a corrente sangüinea por drenagem linfática do sitio absortivo em direção ao canal toráxico, por alguma derivação que exclua os gânglios mesentéricos ou por via desconhecida. $\hat{E}$ de esperar-se que, se o BCG penetrasse nos linfonodos, seriam certamente seqüestrados e fagocitados pelos macrófagos ganglionares. Não pode ser excluida a possibilidade da absorção do BCG pela migração de macrófagos contendo bacilos da lâmina própria ou zona subepitelial para a circulação sistêmica. Isto seria, contudo, um fenòmeno retardado que poderia ocorrer após o pico absortivo do $1{ }^{\circ}$ dia.

O nivel patamar mantido por 18 dias poderia ser explicado pela presença de BCG intacto no figado, mas não significa necessariamente que os bacilos estariam vivos. $\mathrm{Na}$ verdade, nós achamos que bacilos viáveis estavam ausentes dos orgãos dos animais tratados. Ainda que alguns relatos tenham mostrado que BCG administrado por via oral possa ser recuperado de diferentes órgãos, o assunto é ainda controverso. Nossos dados concordam com recente publicação mostrando recuperação de pouquíssimas particulas viáveis de BCG no figado de camundongos, submetidos semanalmente a doses maciças de $\mathrm{BCG}^{28}$. Em adição, Gernez-Rieux e cols ${ }^{10}$ não foram capazes de recuperar BCG viável de linfonodos mesentéricos, de pacientes neoplásicos submetidos a doses altas de BCG oral, a despeito do número significante de bacilos viáveis no suco intestinal.

Tokunaga e cols ${ }^{28}$ mostraram que os macrófagos infiltram as placas de Peyer após administração de BCG oral. Os eventos imunológicos que seguem a infiltração de macrófagos nas placas de Peyer não estão bem estabelecidas, mas nossos resultados sugerem que as células fagociticas poderiam ter restringido a infecção pelo BCG, quando estes estavam danificados pela ação dos sucos digestivos. Apesar de ser bem conhecida a propriedade do BCG oral de induzir reação positiva ao PPD em humanos $\mathrm{e}$ animais $^{2} 181923$, ainda não foi comprovado se esta resposta é equivalente ao nivel de imunidade celular induzida pelo BCG vivo administrado por via intradérmica.

\section{SUMMARY}

The absorption and the biological routing of Mycobacterium bovis $B C G$ vaccine following intragastric administration to mice was studied. A harmful action of gastric (GJ) and duodenal juices (DJ) on BCG cells in vitro was found. Treatment with GJ induced a significant decrease of the oxygen uptake and a moderate loss of viability, as expressed by the number of colony-forming units (CFU) of $B C G$. Severe decreases of bacilli respiration and a notable fall of $C F U$ counts were detected during $D J$ treatment. The biorouting of BCG cells was determi- 
Mortatti RC, Maia LCS, Fonseca L. Ação dos sucos digestivos sobre a absorção e destino do BCG oral. Revista da Sociedade Brasileira de Medicina Tropical 19: 251-258, Out-Dez, 1986.

ned using carbon-14 labelled bacilli. The labelling was accomplished through a metabolic precursor of mycobacterial lipids, ${ }^{14} \mathrm{C} \quad$-glycerol. The levels of radioactivity recovered at the first day in the organs of mice receiving either gastric instillation of ${ }^{14} C-B C G$, sonically disrupted ${ }^{14}-B C G$ or ${ }^{14} C$ glycerol were very similar. Subsequently, sonicated ${ }^{14} C-B C G$ and ${ }^{14} \mathrm{C}-$ glycerol were involved in a biological decay process, while the level of ${ }^{14} \mathrm{C}-\mathrm{BC} \mathrm{G}$ associated radioactivity remained stable in the organs from 6 to 24 days. Data on the biodecay from the small intestine and liver showed that absorptive events were fast enough to reach the highest level at 24 hours, dropping thereafter according to the complexity of the material given to the mice. In all instances, however, living $B C G$ was not cultured from organs of mice given unlabelled $B C G$. The preceding data suggest that the great majority of BCG cells that passed the gut barriers were absorbed intact but not alive.

Key words: Mycobacteria. Oral BCG. Digestive juices. ${ }^{14} \mathrm{C}$-labelling. Absorption. Biovailability.

\section{AGRADECIMENTOS}

Agradecemos ao Dr. Milton Fontes Magarão pelo seu esforço na provisão de financiamentos. Somos gratos tambem ao Dr. Hugo David por seus comentários e proveitosas críticas.

\section{REFERENCIAS BIBLIOGRÁFICAS}

1. Assis A. Concurrent BCG vaccination. Diseases of the Chest 16:266-269, 1949.

2. Assis A. The oral application of BCG. Advances in Tuberculosis Research 8:105-122, 1957.

3. Bailey NTJ. Statistical methods in biology. John Wiley \& Sons Inc. $5^{\text {th }}$ edition, New York, 1959.

4. Baldwin RW, Hopper DG, Pimm MV. Influence of orally administered BCG on growth of transplantable rat tumors. British Journal of Cancer 31:124-128, 1975.

5. Bast RC, Bast BS. Critical review of previously reported animal studies of tumor immunotherapy with nonspecific immunostimulants. Annals of the New York Academy of Sciences 277:60-92, 1976.

6. Calmette A, Well-Halle B, Saenz A, Costil R. Demonstration experimentale du passage de bacilles-vaccins BCG a travers la muqueuse de l'intestin chez l'enfant et chez le sing. Bulletin de l'Academie Nationale de Medecine 110:203-206, 1933.

7. Carter PB, Collins FM. The route of enteric infection in normal mice. Journal of Experimental Medicine 139:1189-1203, 1974.

8. Gernez-Rieux C, Tacquet A, Fabre M, Gerard A, Voisin C. Absorption digestive du BCG chez les cobayes et les souris avant et aprés la vaccination. Annales de l'Institut Pasteur de Lille 6:94-115, 1953-1954.

9. Gernez-Rieux C, Breton A, Tacquet A. Premiers essais d'absorption de $\mathrm{BCG}$ à dose massive et répétés chez les enfants allergiques. Archives Françaises de Pediatrie 11:291-295, 1954.

10. Gernez-Rieux C, Breton A, Tacquet A, Gerard A, Fabre M, Piat M. Vaccination antituberculeuse par voie digestive chez les sujets allergiques. I. Étude experimentale. II. Étude clinique. Revue de Tuberculose et de Pneumologie 18:677-700, 1954.

11. Janicki BW, Wright Jr. GL, Good RC, Chaparas SD. Comparison of antigens in sonic and pressure cell extracts of Mycobacterium tuberculosis. Infection and Immunity 13:425-437, 1976.

12. Joel DD, Laissue JA, LeFreve ME. Distribution and fate of ingested carbon particles in mice. Journal of Reticuloendothelial Society 24:477-487, 1978.

13. LeFreve ME, Olivo R, Joel DD. Accumulation of latex particles in Peyer's patches and their subsequent appearence in villi and mesenteric lymph nodes. Proceedings of the Society of Experimental Biology and Medicine 159:298-302, 1978.

14. LeFreve ME, Hammer R, Joel DD. Macrophages of the mammalian small intestine: a review. Journal of Reticuloendothelial Society 26:553-573, 1979.

15. Lewis MG, Jerry LM, Rodwen TM, Phillips TM, Shibata H, Capek A. Some effects of oral administration of BCG on immune response in cancer patients. In: Lamoureaux G, Turcotte R, Portelance V (eds). BCG in cancer immunotherapy. Grune \& Stratton, New York, p. 339-358, 1976.

16. MacDonald AS, Norvell ST, Bordutha IA. Effects of oral BCG in solid tumors. In: Lamoureaux $G$, Turcotte $R$, Portelance V (eds). BCG in cancer immunotherapy. Grune \& Stratton, New York, p. 133-138, 1976.

17. MacDonald TT, Carter PB. Cell-mediated immunity of intestinal infection. Infection and Immunity 28:516-523, 1980.

18. Magarào MF; Brascher HM, Vargens JR, Mortatti RC, Lima AO. Imunidade humoral e celular em crianças vacinadas com BCG pela via oral. Brazilian Journal of Medical and Biological Research 10:175-180, 1977.

19. Negre L, Bretey J, Roy D. Etude de l'allergie à la tuberculine chez le cobayes par ingestion de grosses doses de BCG. Annales de L'Institut Pasteur 98:1-6, 1960.

20. Olinto $M$. The Brazilian experience in prevention of tuberculosis with a concurrent method of BCG vaccination. Pediatrics 19:833-844, 1957.

21. Pasquier JF, Lucel Y. Preuve autoradiographic du passage intestinal chez la souris de bacilles $B C G$ vivants et de bacilles tuberculeux bovins marques au ${ }^{14} \mathrm{C}$ administrés par voie digestive. Comptes Rendus de Séances de la Société de Biologie 155:1930-1940, 1961.

22. Remington JS, Melton ML, Jacobs L. Chronic toxoplasma infection in the uterus. Journal of Laboratory and Clinical Medicine 58:879-883, 1960.

23. Rosemberg J. Present status of the oral BCG vaccination. O Hospital 42:15-20, 1952.

24. Sanders E, Ashworth CTA. A study of particulate intestinal absorption and hepatocellular uptake. Experimental Cell Research 22:137-145, 1961.

25. Shibata HR, Jerry LM, Lewis MG, Mansel PWA, Capek A, Marquis G. Immunotherapy of human ma- 
Mortatti RC, Maia LCS, Fonseca L. Ação dos sucos digestivos sobre a absorção e destino do BCG oral. Revista da Sociedade Brasileira de Medicina Tropical 19: 251-258, Out-Dez, 1986.

lignant melanoma with irradiated tumor cells, oral BCG and levamisole. Annals of the New York Academy of Sciences 277:355-366, 1976.

26. Snedecor GW, Cochran WG. Statistical methods, $6^{\text {th }}$ edition. The lowa State University Press, Iowa, p. 447$471,1976$.

27. Tepper BS. Differences in the utilization of glycerol and glucose by Mycobacterium phlei. Journal of Bacteriology 95: 1713-1717, 1968.

28. Tokunaga T, Taguchi S, Chino F, Murohashi T. Immunotherapeutic trials of murine and guinea-pig solid tu- mors by oral administration of BCG. Japanese Journal of Medical Science and Biology 32:1-18, 1979.

29. Toma JM, Penderleith IH, Clements DV, Landi S. Observations in immunotherapy of lymphoma and melanoma patients. Clinical and Experimental Immunology 21:82-96, 1975.

30. Varella AD, Bandeira DC, Amorim AR, Calvis LA, Santos IO, Escaleira N, Gentil F. Treatment of disseminated malignant melanoma with high-dose oral $\mathrm{BCG}$. Cancer 48:1353-1362, 1981. 